\title{
Trials and tribulations with artificial liver support
}

\author{
ROGER WILLIAMS
}

From the Liver Unit, King's College Hospital and Medical School, Denmark Hill, London

SUMMARY This paper reviews the experience gained over the past few years in two techniques of liver support, charcoal haemoperfusion and polyacrylonitrile membrane haemodialysis. Problems with charcoal haemoperfusion have centred around platelet aggregation and hypertension, and new carbon preparations with a variety of different coatings to overcome these problems are described. Haemodialysis using the PAN membrane has caused fewer side-effects and current results show that $33 \%$ of patients so treated recover consciousness. The new techniques for liver support currently being developed, including combined dialysis/perfusion systems and those based on plasma separation, are also described.

It is a great pleasure for me to contribute to this special volume, for my interest in liver disease was fostered and developed during five formative years with Professor Sherlock in 'that hut' at the Royal Free Hospital.

The development of a reproducible and efficient form of liver support could do as much for patients with liver disease as the introduction of kidney dialysis did for those with severe renal conditions. Not only are there the patients with fulminant liver failure, in whom mortality remains at over $80 \%$ despite advances in supportive therapy, but there are the patients awaiting liver transplants-some of whom may require preoperative support, as well as those with acute alcoholic hepatitis and other conditions with acute decompensation of hepatic function in whom recovery is potentially possible.

In the following pages I shall concentrate on the two techniques with which we have been much concerned over the past few years-namely, charcoal haemoperfusion and polyacrylonitrile membrane haemodialysis.

\section{Charcoal haemoperfusion}

The two major technical problems identified by Yatzidis, who was the first to report direct blood haemoperfusion over charcoal granules for uraemia and barbiturate intoxication (Yatzidis et al., 1965), related to the release of charcoal powder ('fines') into the circulation, resulting in embolism to various organs, and depletion of platelets and leucocytes as a result of damage to them during haemoperfusion.

Most of the work since then has been directed towards the development of a biocompatible coating to separate the charcoal from the blood. which would be permeable to the desired toxins but not to platelets and leucocytes (microencapsulation). Another approach, which has attracted more attention recently, involves the separation of plasma from blood before its perfusion over charcoal, and this will be considered later in this review.

\section{DIFFERENT VARIETIES OF CHARCOAL AND MICROENCAPSULATION}

\section{Albumin-colloidion encapsulated charcoal}

After testing a large number of possible membrane materials, Chang and co-workers developed an encapsulated preparation in which the prewashed and sterilised coconut charcoal granules are coated with an ultrathin membrane of colloidion to which a second coating of human albumin is then absorbed (Chang, 1969; Chang, 1972).

\section{Poly-hydroxyethyl methacrylate (polyhema) encapsulated charcoal}

The original observations of Andrade and colleagues (1971) that microencapsulation with polyhydroxyethyl methacrylate (polyhema) caused a significant reduction in platelet loss led Fennimore and co-workers (1974), of Smith \& Nephew Research Ltd, further to develop the preparation which was used by us in the initial clinical studies of charcoal haemoperfusion in fulminant hepatic failure (Gazzard et al., 1974).

\section{Use of co-polymers and cellulose}

This has been the approach adopted by the group working at Strathclyde (Courtney et al., 1977), 
whose most recent preparation consists of a peatbased charcoal, spray-coated with cellulose acetate dissolved in acetic acid which is then converted to a cellophane membrane (cellulosic) (Thysell et al., 1976).

\section{Encapsulated petroleum pitch charcoal}

This preparation, pioneered by Ohta and his colleagues in Japan, has properties quite different from the coconut and peat-based charcoal preparations. The granules are hard, spherical in shape (0.8-1.2 $\mathrm{mm}$ diameter), and have a smooth surface appearance on scanning electron microscopy (Amano et al., 1976; 1978). Encapsulation is with a colloidion membrane.

For each of these preparations there is evidence derived from animal studies given in the references quoted above to show that the coating confers biocompatibility with respect to preservation of platelets (Gazzard et al., 1974; Chang, 1977; Courtney et al., 1977). However, the results of at least one clinical trial in patients with fulminant hepatic failure, in which the polyhema coated charcoal preparation was used (Weston et al., 1977), suggest that the biocompatibility in the clinical situation cannot be reliably predicted from the results of animal studies.

\section{ADSORPTIVE PROPERTIES OF MICROEN- CAPSULATED CHARCOALS}

The many factors here include the source of the charcoal, the size of the granules, and the pore size, as well as the type, thickness, and the pore size of the coating. In general, low molecular weight water soluble compounds (MW $<500$ ) are avidly adsorbed by all the preparations. With respect to the specific compounds in this molecular weight range, 'popularly' held to be important in the development of acute hepatic encephalopathy, amino acids, free phenols, and fatty acids have all been shown to be bound (Gazzard et al., 1974; Abouna et al., 1975; Amano et al., 1978; Silk and Williams, 1978). Ammonium, however, which at physiological pH is heavily ionised, appears to be poorly adsorbed.

Compounds in the middle molecular weight range (500-5000) are also known to be adsorbed (Chang, 1975; Amano et al., 1978; Opolon et al., 1977) but, of the preparations that are currently available, the thinly encapsulated, large pore size $\left(10^{\circ}-80^{\circ} \mathrm{A}\right)$, petroleum pitch-based charcoal appears to have the greatest binding affinity.

Compared to water soluble compounds, those bound to plasma proteins are poorly adsorbed (Chang, 1975; Dunlop et al., 1975), although, if the binding is loose, as with the drugs glutethamide and methaqualone, adequate removal from the circulation of intoxicated patients can be obtained (Volans et al., 1977). It is to be appreciated also that, if an exterior coating of human serum albumin is used, adsorption of protein bound compounds is likely to be enhanced, as albumin molecules with free binding sites compete for toxins bound to carrier proteins in perfused blood (Plotz et al., 1974).

\section{EXPERIMENTAL EVALUATION OF CHARCOAL} HAEMOPERFUSION

In the first evaluation of charcoal haemoperfusion in a large animal model of acute liver failure based on hepatic devascularisation which we reported, haemoperfusion was started immediately after surgery was completed. Mean survival time was significantly prolonged compared with control animals (Weston et al., 1974). Furthermore, levels of arterial blood ammonia rose progressively in the controls, whereas in the charcoal haemoperfusion group there was no rise. However, using a very similar dog model, Abouna et al. $(1975,1977)$ could find no statistically significant improvement in survival, either with the initial or the most recent preparation of encapsulated peat-based charcoal. Opolon and colleagues (1977) have also recently reported in a pig model that charcoal haemoperfusion had no effect on survival or in correcting raised false neurotransmitter levels in the brain or blood ammonia levels. However, as in the two series of Abouna, and in contrast to the treatment schedule adhered to by Weston et al. (1974), perfusion was not instituted until several hours after completion of surgery. In the recent study from Chang's group, in which they showed that a one hour period of haemoperfusion significantly inincreased survival in rats with galactosamineinduced hepatic damage (Chirito et al., 1977), charcoal haemoperfusion was instituted early.

CLINICAL USE IN FULMINANT HEPATIC FAILURE

The King's College Hospital experience with charcoal haemoperfusion, comprising as it did the first large series of patients with fulminant hepatic failure treated by repeated daily charcoal haemoperfusion, was reported by Gazzard et al. (1974). Ten of 22 patients with fulminant hepatic failure, all of whom showed signs of grade IV coma before treatment survived to leave hospital. However, of the subsequent 34 patients treated, only three $(8 \cdot 8 \%)$ survived, and hypotensive reactions occurred very much more frequently than in the initial series.

Observations that the severe hypotensive reactions 
were associated with variable losses of circulating platelets, led Weston et al. (1977) to carry out detailed studies of platelet function. Not only were the patients found to have a greater percentage of small platelets in the total count before treatment, but there was an additional loss of the larger and metabolically more active platelets during haemoperfusion. Platelet aggregation as a result of passage of blood through the charcoal appeared to be the most likely explanation of this loss. Direct evidence of this was obtained from the marked rises recorded in the Swank screen filtration pressure of blood leaving the columns. A close temporal relationship was also observed between the rises in filtration pressure and fall in blood pressure, and the release of vasoactive amines from platelet aggregates could well explain the relationship found (Weston et al., 1977; Williams, 1977; Silk and Williams, 1978). Why this was such a problem in the later series of perfusions only is still unclear.

A smaller number of patients with fulminant hepatic failure have been treated by repeated charcoal haemoperfusion using the same coconut-based charcoal but encapsulated with $2 \%$ rather than $4 \%$ polyhema both in the USA (Gelfand et al., 1976, 1977) and in Germany (Bartels et al., 1976; Blume et al., 1976). Recovery of consciousness was observed in some patients and a few survived to leave hospital. Significant platelet losses were recorded, but, contrary to the later experiences of the King's group, damaging hypotensive reactions were not observed. Of possible clinical relevance was the demonstration in one of these studies (Bartels et al., 1976) of the removal during charcoal haemoperfusion of a number of hormones including cortisol, aldosterone, tri-iodothyronine, thyroxin, glucagon, and insulin.

The newly developed petroleum pitch-based charcoal has been evaluated clinically in Japan. The system used combines charcoal haemoperfusion and haemodialysis with a cupraphane membrane, and, so far, 15 patients with fulminant hepatic failure have been treated (Amano et al., 1977). Five patients partially recovered consciousness, and $20 \%$ survived to leave hospital. Platelet losses during a single perfusion were up to $50 \%$ of initial levels, but no severe hypotensive reactions were observed. Clinical use of the support system was associated with an average reduction of $26.2 \%$ in plasma amino acid levels and these workers have also studied the changes in amino acid levels in cerebrospinal fluid. Although no changes were found immediately after haemoperfusion, when they were measured five hours later an average reduction of $18.2 \%$ was observed in those patients who had shown improvements in EEG grading.
Yamazaki and colleagues (1977) have used a somewhat different system in which plasma is separated from whole blood by passage through cellulose acetate hollow fibres before perfusion over the 'charcoal'. So far, 13 patients with fulminant hepatic failure have been treated. Some improvement in consciousness was observed in nine, and five of these $(38.5 \%$ of total) survived to leave hospital.

\section{Haemodialysis with polyacrylonitrile membrane}

If retention of water soluble toxins of low molecular weight is important in the pathogenesis of acute hepatic failure, standard methods of dialysis should result in an adequate plasma clearance. Some clinical reports have, indeed, described reduction in blood ammonia levels, although improvement in conscious level and survival have been less impressive. Furthermore, Opolon and colleagues, in an elegant series of experiments in a pig model of acute liver failure, have not only shown that conventional cuprophane haemodialysis has no effect on deterioration of consciousness, EEG impairment, and survival time, but also that this dialysis system was without effect on regional concentrations of brain neurotransmitters and their precursor amino acids (Opolon et al., 1976; Bloch et al., 1978). In contrast, haemodialysis using the much more permeable polyacrylonitrile membrane had a markedly beneficial effect on levels of consciousness and EEG recordings, and at the end of dialysis brain neurotransmitter concentrations were within normal limits. This difference between the two membranes on neurotransmitter concentrations suggested that the beneficial effect on conscious level might be related to removal of compounds in the middle molecular weight range (1500-5000 daltons). Significant improvement in conscious levels of patients with fulminant hepatic failure have been reported by this group (Opolon et al., 1975; Opolon, 1978), and, although final percentage survival figures are not appreciably better than those achieved by conservative therapy alone, periods of survival were significantly prolonged.

Our own experience at King's is also encouraging (Silk et al., 1977; Silk and Williams, 1978). Sixty-five patients with fulminant hepatic failure and signs of grade IV encephalopathy have now been treated by repeated daily (four to six hours) haemodialysis. Twenty of those $(30.8 \%)$ have survived to leave hospital, results which are to be compared with a survival rate of $15 \%$ of 53 similar patients treated by standard conservative therapy alone. In contrast to the experience of Opolon and co-workers, all 
but one of the patients who recovered consciousness survived to leave hospital and, in our experience, it is unusual for an improvement in consciousness levels not to be sustained in patients treated by polyacrylonitrile haemodialysis.

Since the dialysis fluid is circulated in a closed system, accurate measurement of the total amounts of each individual amino acid removed from the circulation of these patients is possible. Our results show that the equivalent of at least five plasma pools of each amino acid was removed during a four hour haemodialysis period (Chase et al., 1978). This gives an indication of the rapidity with which amino acids are transferred from tissue to plasma pools in patients with fulminant hepatic failure, and explains how, despite substantial removal by sorbent-perfusion or haemodialysis systems, circulating amino acid levels after treatment may not be substantially different from those measured before. If one believes that it is the rises in plasma level that underlie the development of encephalopathy, then the rate of tissue to plasma re-equilibration during liver support is likely to be of key importance. At present, most patients are treated for periods of three to six hours daily, but, if the tissue to plasma movement of other potentially toxic metabolities is as rapid as amino acids, then circulating plasma levels may be effectively lowered only by substantially prolonging each treatment period.

\section{Combined dialysis/perfusion system}

The use of plasma rather than whole blood for adsorbent perfusion as one way of avoiding damage to the formed elements of the blood has already been referred to. In the technique being developed by Nosé et al. (1977), plasma is separated from blood elements by filtration through a microporous membrane and then reunited with the bulk flow after contact with charcoal in a reactor compartment (plasma filtration haemoperfusion). In normal calves this technique has been shown to cause only minimal damage to formed blood elements (Castino et al., 1976). In the somewhat similar technique developed by the Strathclyde Bioengineering Unit, the core of their proposed hepatic support system is a haemodialyser constructed with membranes of very high porosity that permit passage of serum proteins but not the cellular constituents of blood. The separated plasma is then circulated through a cartridge containing large quantities of mixed sorbents including activated carbon (Maini et al., 1977).

TIMING OF CONTROLLED CLINICAL TRIAL AND OTHER NEW DEVELOPMENTS

Criticisms have been levelled at some groups for failing to perform randomly allocated controlled clinical trials of charcoal haemoperfusion in fulminant hepatic failure (Berk, 1978; Ware, 1977). When the full facts are considered, however, it becomes evident that circulating protein-bound as well as water soluble, metabolites probably play an important role in the pathogenesis of the coma in these patients (Zieve, 1975). The various encapsulated charcoal preparations currently available do not in general have high adsorptive capacities for protein-bound toxins, and in our view an effective liver support system based on haemoperfusion will have to have the capacity for removing all classes of toxic metabolites from the circulation of these patients.

Advances are being made, though more slowly, towards the development of a biocompatible resin for removing protien-bound compounds. Of the resins so far tested, those in the Amberlite series (XAD-2, 4, and 7) appear to be most effective in adsorbing protein-bound toxins such as bilirubin and bile salts (Willson, 1975). In very recent studies we have shown that it is possible to bind human serum albumin tightly to Amberlite XAD-7 resin and that this, as evidenced by in vitro haemoperfusion experiments, substantially improves the biocompatibility of the resin with respect to platelet losses (Hughes et al., 1978).

Lastly, and most importantly, it has now become widely appreciated that no form of liver support therapy can be expected to be effective if it is not instituted until the preterminal stage in the illness when cerebral oedema and other complications are already established (Hanid et al., 1978). Indeed, our own experience with haemodialysis and charcoal haemoperfusion suggest that such patients should not be excluded from future evaluations of liver support systems. A retrospective analysis of 92 of our cases has shown that more than $90 \%$ of those admitted in grade III ultimately progressed to grade IV coma. It would, therefore, seem logical to institute liver support much earlier in the course of the illness.

\section{References}

Abouna, G. M., Barabas, A. Z., Boyd, N., Todd, J. K., Alexander, F., Kinniburgh, D. W., Gilchrist, T., and Jonsson, E. (1977). Resin and charcoal haemoperfusion in the treatment of hepatic coma. In Artificial Organs, pp. 363-371. Edited by R. M. Kenedi, J. M. Courtney, J. D. S. Gaylor, and T. Gilchrist. Macmillan: London. Abouna, G. M., Gilchrist, T., Pettit, J. E., Boyd, N. D., Todd, J. K., Courtney, J. M., and Maini, R. (1975). Haemoperfusion with activated charcoal in treatment of experimental acute hepatic failure. In Artificial Liver Support, pp. 180-185. Edited by R. Williams and I. M Murray-Lyon. Pitman Medical: London.

Amano, I., Kano, H., Saito, A., Manji, T., Yamamoto, Y., 
Iwatsuki, S., Takahira, H., Ohta, K., and Maeda, K. (1976). Efficacy of petroleum charcoal haemoperfusion and acetate-free dialysate in 10 patients with hepatic coma. Proceedings of the European Dialysis and Transplant Association, 13, 262-272.

Amano, I., Kano, H., Takahira, H., Yamamoto, Y., Itoh, K., Iwatsuki, S., Maeda, K., and Ohta, K. (1978). Hepatic assist system using bead-type charcoal. In Artificial Liver, and Detoxication, edited by T. M. S. Chang. Plenum: New York. (In press.)

Andrade, J. D., Kunitomo, K., Van Wagenen, R., Kastigir, B., Gough, D., and Kolff, W. J. (1971). Coated adsorbents for direct blood perfusion: HEMA-activated carbon. Transactions of the American Society for Artificial Internal Organs, 17, 222-228.

Bartels, O., Neidhardt, B., Neidhardt, M., Schellberger, H., Issel, W., Waldherr, A., and Demling, L. (1976). Untersuchungen und Erfahrungen mit der Kohle-Hämoperfusion bei Leberkoma. In Entgiftung mit Hämoperfusion, pp. 119-131. Edited by L. Demling and O. Bartels. Carl Bindernagel: Friedberg.

Berk, P. D. (1978). Historical perspectives and present status of the treatment of liver failure. In Novel Approaches in Artificial Kidney, Artificial Liver, and Detoxification, edited by T. M. S. Chang. Plenum Publishing Corporation, New York. (In press).

Bloch, P., Delorme, M. L., Rapin, J. R., Granger, A., Boschat, M., Opolon, P. (1978). Reversible modifications of brain neurotransmitters in experimental acute hepatic coma. Surgery, Gynecology, and Obstetrics. (In press.)

Blume, U., Helmstaedt, D., Sybrecht, G., Baldamus, C., Sussman, P., Heyer, U., Schmidt, E., and Schmidt, F. W. (1976). Hämoperfusionstherapie des akuten Leberversagens. Deutsche Medizmische Wochenschrift, 101, 559.

Castino, F., Scheucher, K., Malchesky, P. S., Koshino, I., and Nosé, Y. (1976). Micro-emboli-free blood detoxification utilizing plasma filbration. Transactions of the American Society for Artificial Internal Organs, 22, 637-645.

Chang, T. M. S. (1969). Removal of endogenous and exogenous toxins by a microencapsulated absorbent.. Canadian Journal of Physiology and Pharmacology, 47, 1043-1045.

Chang, T. M. S. (1972). Artificial Cells. Thomas: Springfield, Ill.

Chang, T. M. S. (1975) Experience with the treatment of acute liver failure patients by haemoperfusion over biocompatible microencapsulated (coated) charcoal. In Artificial Liver Support, pp. 229-233. Edited by R. Williams and I. M. Murray-Lyon. Pitman: London. Chang, T. M. S. (1977). Protective effects of microencapsulation (coating) on platelet depletion and particulate embolism in the clinical applications of charcoal haemoperfusion. In Artificial Organs, pp. 164-177. Edited by R. M. Kenedi, J. M. Courtney, J. D. S. Gaylor, and T. Gilchrist. Macmillan: London.

Chase, R. A., Davies, M., Trewby, P. N., Silk, D. B. A., and Williams, R. (1978). Plasma amino acid profiles in patients with fulminant hepatic failure treated by repeated polyacrylonitrile membrane haemodialysis. (Submitted for publication).

Chirito, E., Reiter, C., and Chang, T. M. S. (1977) Artificial liver: the effect of ACAC microencapsulated charcoal haemoperfusion on fulminant hepatic failure. Artificial Organs, 1, 76-83.

Courtney, J. M., Fairweather, I. A., Gilchrist, T., Hood, R. G., Park, G. B., and Smith, E. M. (1977). The design of a polymer coating for activiated carbon. In Artificial Organs, pp. 133-138. Edited by R. M. Kenedi, J. M.
Courtney, J. D. S. Gaylor and T. Gilchrist. Macmillan: London.

Dunlop. E. H., Weston, M. J., Gazzard, B. G., Langley, P. G., Mellon, P. J., and Williams, R. (1975). Artificial liver support based on haemoperfusion of adsorbents. Biomedical Engineering, 10 (6), 231-218.

Fennimore, J., Watson, P. A., Munro, G. D., and Kothammer, J. C. (1974) The design and evaluation of a convenient carbon haemoperfusion system. Proceedings of the European Society for Artificial Organs, 1, 90-99.

Gazzard, B. G., Weston, M. J., Murray-Lyon, I. M., Flax, H., Record, C. O., Portmann, B., Langley, P. G., Dunlop, E. H., Mellon, P. J., Ward, M. B., and Williams, R. (1974). Charcoal haemoperfusion in the treatment of fulminant hepatic failure. Lancet, 1, 1301-1307.

Gelfand, M. C., Colon, A., Knepsheild, J. H., Papadopoulou, Z., Sandler, P., and Schreiner, G. E. (1977). Successful management of stage IV hepatic coma in a child by haemocarboperfusion. In Artificial Organs, pp. 425-428. Edited by R. M. Kenedi, J. M. Courtney, J. D. S. Gaylor, and T. Gilchrist. Macmillan: London.

Gelfand, M. C., Knepsheild, J. H., Cohan, S., Ramirez, B., and Schreiner, G. C. (1976). Treatment of hepatic coma with hemoperfusion through polyacrylamide hydrogelcoated charcoal. Kidney International, 10, Supp. 7, 239-243.

Hanid, M. A., Mackenzie, R. L., Jenner, R. E., Chase, R. A., Mellon, P. J., Trewby, P. N., Janota, I., Davis, M., Silk, D. B. A., and Williams, R. (1978). Intracranial pressure in pigs with surgically induced acute liver failure. (Submitted for publication.)

Hughes, R. D., Ton, H. Y., Langley, P. G., Silk, D. B. A., and Williams, R. (1978). Blood compatibility of albumin coated XAD-7 resin for use in artificial liver support systems. Proceedings of the European Society for Artificial Organs. (In press.)

Maini, R., Baillie, H., and Stark, M. (1977). Hepatic support system utilising high-porosity protein-permeable membranes in conjunction with dialysate regeneration. In Artificial Organs, pp. 395-402. Edited by R. M. Kenedi, J. M. Courtney, J. D. S. Gaylor, and T. Gilchrist. Macmillan: London.

Nosé, Y., Malchesky, P. S., Koshino, I., Castino, F., and Scheucher, K. (1977). Hepatic assist, 2. Devices for use with sorbents and biological reactors. In Artificial Organs, pp. 378-387. Edited by R. M. Kenedi, J. M. Courtney, J. D. S. Gaylor, and T. Gilchrist. Macmillan: London.

Opolon, P. (1978). High permeability membrane hemodialysis in acute hepatic coma: Experimental and clinical results. In Proceedings of the Second International Symposium for Artificial Organs, Tokyo. (In press.)

Opolon, P., Javaudin, L., Delorme, M. L., Boschat, M., and Rapin, J. R. (1978). Charcoal haemoperfusion and brain neurotransmitters in experimental liver failure. In Proceedings of the European Society for Artificial Organs. (In press.)

Opolon, P., Lavallard, M. C., Crubille, C., Gateau, P. Nusinovici, V., Granger, A., Darnis, F., and Caroli, J. (1975). Encéphalopathie au cours de l'atrophie hépatique aigue. Effet de l'épuration des moyennes molécules. Résultats préliminaires. Nouvelle Presse Medicale. 4, 2987-2991.

Opolon, P., Lavallard, M. C., Huguet, C., Bidallier, M., Granger, A., Gallot, D., and Bloch, P. (1976). Hemodialysis versus cross hemodialysis in experiemtal hepatic coma. Surgery, Gynecology and Obstetrics, 142, 845-854.

Plotz, P. H., Berk, P. D., Scharschmidt, B. F., Gordon, J. K., and Vergalla, J. (1974). Removing substances from blood by affinity chromatography I. Removing bilirubin and other albumin-bound substances from plasma and blood with albumin-conjugated agarose heads. Journal of 
Clinical Investigation, 53, 778-785.

Silk, D. B. A., Hanid, M. A., Trewby, P. N., Davies, M., Chase, R. A., Langley, P. G., Mellon, P. J., Wheeler, P. G., and Williams, R. (1977) Treatment of fulminant hepatic failure by polyacrylonitrile-membrane haemodialysis. Lancet, 2, 1-3.

Silk, D. B. A., and Williams, R. (1978). Experiences in the treatment of fulminant hepatic failure by conservative therapy, charcoal haemoperfusion, and polyacrylonitrile haemodialysis. International Journal of Artificial Organs, 1, 29-33.

Thysell, H., Lindholm, T., Heinegard, D., Jonsson, E., Nyclen, U., Strensson, T., Bergkuist, G., and Gullberg, C. A. (1976). A haemoperfusion column using cellophane coated charcoal. Proceedings of the European Society for Artificial Organs, 2, 212-218.

Volans, G. N., Vale, J. A., Crome, P., Widdop, B., and Goulding, R. (1977). The role of charcoal haemoperfusion in the management of acute poisoning by drugs. In Artificial Organs, pp. 178-187. Edited by R. M. Kenedi, J. M. Courtney, J. D. S. Gaylor, and T. Gilchrist. Macmillan: London.

Ware, A. (1977). Polyacrylonitrile membrane dialysis for hepatic coma (Letter). Lancet, 2, 451.

Weston, M. J., Gazzard, B. G., Buxton, B. H., Winch, J., Machado, A. L., Flax, H., and Williams, R. (1974). Effects of haemoperfusion through charcoal or XAD-2 resin on an animal model of fulminant hepatic failure.
Gut, 15, 482-486.

Weston, M. J., Langley, P. G., Rubin, M. H., Hanid, M. A., Mellon, P. J., and Williams, R. (1977). Platelet function in fulminant hepatic failure and effect of charcoal haemoperfusion. Gut, 18, 897-902.

Williams, R. (1977). Approaches to the development of artificial liver support, In Artificial Organs, pp. 403-412. Edited by R. M. Kenedi, J. M. Courtney, J. D. S. Gaylor, and T. Gilchrist. Macmillan: London.

Willson, R. A. (1975). Resins as adsorbents-including experimental studies in dogs with obstructive jaundice. In Artificial Liver Support, pp. 109-117. Edited by R. Williams and I. M. Murray-Lyon. Pitman: London. Yamazaki, Z., Fujimori, Y., Sanjo, K., Kohima, Y., Sugiura, M., Wada, T., Inoue, N., Sakai, T., Oda, T., Kominami, N., Fujisaki, U., and Kataoka, K. (1978). New artificial liver support system (plasma perfusion detoxification) for hepatic coma. In Proceedings of the Second International Symposium for Artificial Organs, Tokyo. (In press.)

Yatzidis, H., Oreopoulos, D., Triantaphyllidis, D., Voudiclari, S., Tsaparas, N., Gavras, C., and Stavroulaki, A. (1965). Treatment of severe barbiturate poisoning. Lancet, 2, 216-217.

Zieve, L. (1975). Metabolic abnormalities in hepatic coma and potential toxins to be removed. In Artificial Liver Support, pp. 11-26. Edited by R. Williams, and I. M. Murray-Lyon. Pitman: London. 